\title{
As leis do período militar e seus reflexos sobre o trabalho e o trabalhador
}

\author{
The laws of the military period and its reflections on work \\ and worker
}

Las leyes del período militar y sus reflejos sobre el trabajo y el trabajador

Maria Augusta Castilho ${ }^{1}$ Monizzi Mábile Garcia Oliveira² Pedro Pereira Borges ${ }^{3}$

${ }^{1}$ Docente do Programa de Pós-Graduação em Desenvolvimento LocalMestrado/Doutorado e no Curso de História da Universidade Católica Dom Bosco (UCDB). E-mail: m.a.castilho@terra.com.br

${ }^{2}$ Acadêmica do 8o semestre do Curso de Graduação em História e bolsista do PIBIC da Universidade Católica Dom Bosco (UCDB).

E-mail: monizzi.mg@gmail.com

${ }^{3}$ Doutor em História Social. Docente no Programa de Pós-graduação em Desenvolvimento Local da Universidade Católica Dom Bosco (UCDB). E-mail: pobojari@ucdb.br 
Resumo: O estudo resulta da análise dos processos trabalhistas do Tribunal Regional do Trabalho- MS dos anos de 1964 a 1969, vinculado ao projeto, "Análise dos processos trabalhistas do Tribunal Regional do Trabalho- MS (1962-1984)", estabelecido via convênio com o TRT da 24a Região MS, junto com a Universidade Católica Dom Bosco. A pesquisa objetiva contribuir para a conservação da memória do trabalho e do trabalhador no Brasil, em especial no estado de MT/MS, no período de 1964 a 1969. A metodologia foi pautada no método dedutivo via análise documental e embasamento teórico, voltado para consultas/ leituras bibliográficas em livros, jornais, artigos sobre a memória do trabalho e das leis trabalhistas brasileiras. Foram feitos levantamentos das leis trabalhistas criadas ou adaptadas durante o período analisado, época em que o país vivia um processo de ditadura militar e análises de diversos processos sobre as situações dos trabalhadores no período analisado.

Palavras-chave: memória; leis trabalhistas; processos; trabalhador; território.

\begin{abstract}
The study results from the analysis of the labor lawsuits of the Regional Labor Court - MS from 1964 to 1969, linked to the project, "Analysis of labor lawsuits of the Regional Labor Court- MS (1962-1984)", established by agreement With the TRT of the 24th MS Region, together with the Dom Bosco Catholic University. The research aims to contribute to the preservation of the memory of work and of the worker in Brazil, especially in the state of MT / MS, from 1964 to 1969. The methodology was based on the deductive method through documentary analysis and theoretical background, / Bibliographical readings in books, newspapers, articles on the memory of labor and Brazilian labor laws. Surveys were made of labor laws created or adapted during the period analyzed, at a time when the country was undergoing a military dictatorship and analyzes of various processes on the situation of workers in the period analyzed.
\end{abstract}

Keywords: memory; work laws; processes; worker; territory.

Resumen: El estudio resulta del análisis de los procesos laborales del Tribunal Regional del Trabajo- MS de los años 1964 a 1969, vinculado al proyecto, "Análisis de los procesos laborales del Tribunal Regional del Trabajo- MS (1962-1984)", establecido vía convenio Con el TRT de la 24a Región MS, junto con la Universidad Católica Don Bosco. La investigación objetiva contribuir a la conservación de la memoria del trabajo y del trabajador en Brasil, en especial en el estado de MT / MS, en el período de 1964 a 1969. La metodología fue pautada en el método deductivo a través del análisis documental y de la base teórica, orientado a consultas / Lecturas bibliográficas en libros, periódicos, artículos sobre la memoria del trabajo y de las leyes laborales brasileñas. Se realizaron levantamientos de las leyes laborales creadas o adaptadas durante el período analizado, época en que el país vivía un proceso de dictadura militar y análisis de diversos procesos sobre las situaciones de los trabajadores en el período analizado.

Palabras clave: memoria; leyes laborales; procesos; trabajador; territorio. 


\section{INTRODUÇÃO}

O presente artigo faz parte da pesquisa sobre as leis trabalhistas durante a ditadura militar e seus reflexos sobre o trabalho e o trabalhador. O estudo está vinculado ao plano de trabalho da análise dos processos trabalhistas do Tribunal Regional do Trabalho- MS (1964-1969), vinculado ao projeto em andamento, análise dos processos trabalhistas do Tribunal Regional do Trabalho de Mato Grosso do Sul (1962-1984), estabelecido via convênio com o Tribunal Regional do Trabalho da 24a Região MS, desenvolvido no Laboratório de História (LABHIS) da Universidade Católica Dom Bosco. O objetivo do estudo é descrever de forma sintética, aspectos históricos, geográficos e sociais encontrados nos processos e suas relações com o mundo do trabalho, destacando os acontecimentos ocorridos em âmbito nacional no período da ditadura militar brasileira.

Nesse contexto, a pesquisa pretende contribuir com conservação da memória do trabalho e do trabalhador no Brasil e, em especial, do estado de Mato Grosso e Mato Grosso do Sul, assinalando como a justiça do trabalho foi se adaptando e contribuindo com as leis que foram sendo instituídas gradativamente no país. A metodologia utilizada para desenvolver o estudo foi realizada por meio da análise documental e, para dar embasamento teórico consistente, optou-se por consultas/leituras bibliográficas a respeito da memória do trabalho e das leis trabalhistas. Nesse primeiro momento, foram feitos levantamentos das leis trabalhistas implementadas ou adaptadas durante o período de 1964 a 1969, período este em que o país vivia um processo de ditadura militar e, em contraponto com esse levantamento, foram feitas análises dos processos de número: 185, 183, 431, 346, 367, $391,153,335,165,167,168,170,171,174,175,176,179,180,192,191$, $195,214,224,214,213$, referentes ao ano de 1964 e os processos de $n$. 270 do ano de 1965.

\section{CENÁRIO POLÍTICO DURANTE O PERÍODO MILITAR}

O período que antecede o golpe militar foi marcado por grandes tensões, após a renúncia de Jânio Quadros (1961) e o início da tentativa de anular a posse de João Goulart (1961-1964), que assume a presidência de 
forma figurativa sob um governo parlamentarista, que durou cerca de dois anos (BARROS, 1994). No dia 6 de janeiro de 1963, Goulart realizou plebiscito em que recuperou seus plenos poderes como presidente. Durante o governo de Jango, havia duas linhas ideológicas partidárias completamente opostas, a frente popular e o projeto conservador. A frente popular ofereceu seu apoio ao governo de Jango; os ideais políticos desse grupo iam ao encontro dos ideais do presidente, reunindo movimentos populares e nacionalistas. As elites davam seu apoio ao projeto conservador, temia-se a popularização dos bens de consumo e a sombra do comunismo que pairavam sobre os interesses desses grupos (MOTA; LOPEZ, 2008).

No dia 13 de março de 1964, Goulart fazia seu discurso na Central do Brasil reunindo cerca de 200 mil pessoas. As palavras do presidente a favor da reforma agrária, eleitoral e bancária foram suficientes para reforçar a conspiração que vinha sendo feita pelas forças conservadoras, alegando-se que Goulart iria implantar o comunismo no país (BARROS, 1994). A partir desse acontecimento, a situação política se acirrou ainda mais; cerca de um mês após o discurso na Central do Brasil, o poder foi tomado pelos militares concretizando assim o golpe militar. No dia primeiro de abril de 1964, o Senador Auro Soares de Moura Andrade declarava vaga a cadeira da Presidência da República do Brasil, Jango viajou para São Borja e de lá seguiu para seu exílio no Uruguai. "[...] somente no dia 15 de abril de 1964, após a operação limpeza estipulada pelo Comando Supremo da Revolução, é que Castelo Branco toma posse [...]" (ABREU, 2011, p. 26).

O governo militar começou a desenvolver suas atividades políticas por meio de Atos Institucionais, o que possivelmente permitiria que todas as decisões tomadas pelo novo governo fossem constitucionais. Nesse sentido, as leis a respeito do trabalho e do trabalhador foram estabelecidas nesse período. Entre as questões que levaram o Brasil à ditadura militar são perceptíveis no documento A-1, no qual se identificou que havia forças ideológicas diferentes que disputavam o poder no país.

Para demonstrar que não pretendemos radicalizar o processo revolucionário, decidimos manter a Constituição de 1946, limitando-nos a modificá-la, apenas, na parte relativa aos poderes do Presidente da República, a fim de que este possa cumprir a missão de restaurar no Brasil a ordem econômica e financeira e tomar as urgentes medidas 
destinadas a drenar o bolsão comunista, cuja purulência já se havia infiltrado não só na cúpula do governo, como nas suas dependências administrativas. (BRASIL, 1964a).

De acordo com o artigo 18 do mesmo ato, todos os partidos políticos do período foram extintos, e cancelados os respectivos registros. Restaram assim, apenas dois partidos participantes no cenário político do período militar, o Movimento Democrático Brasileiro (MDB) e a Aliança Renovadora Nacional (ARENA); dentre os artigos do ato adicional número 2 (A-2), foram estabelecidas várias regras para a permanência e criação de novos partidos, dentre eles o seguimento da Lei n. 4.740, de 15 de julho de 1965 que previa:

Art. 18. O programa dos partidos deverá expressar o compromisso de defesa e aperfeiçoamento do regime democrático definido na Constituição.

Art. 44. Por deliberação das convenções nacionais, dois ou mais partidos poderão fundir-se, num só ou incorporar-se um ao outro.

$\S 1$ o No primeiro caso, observar-se-ão as seguintes normas:

I- os diretórios dos partidos elaborarão projetos comuns de estatutos e programa;

II- os partidos reunidos em uma só convenção nacional, por maioria absoluta, votarão os projetos e elegerão o diretório nacional que promoverá o registro do novo partido. (BRASIL, 1965a).

Segundo Henriques (2014), no MDB, liberais e democratas se aliaram aos comunistas do Partido Comunista Brasileiro (PCB) e, mais tarde, a várias outras forças de esquerda, uma vez destroçadas as tentativas de luta armada.

A extinção dos partidos fez parte do estopim para a divisão dos ideais dos partidários de esquerda, o MDB foi o partido em que políticos com ideias liberais encontraram lugar para permanecer no cenário político do período militar, vereadores que antes do golpe eram do PCB se candidataram pelo MDB. Dessa forma, suas ideias não seriam completamente anuladas pelo regime. Isso fez com que as divergências dentro da oposição aumentassem, o que gerou o enfraquecimento do movimento contra o golpe militar, a desunião dos opositores fortaleceu o regime (MOTTA, 2008). 


\section{LEGISLAÇÕES TRABALHISTAS}

Após a eleição de Costa de Silva como o primeiro presidente representante do regime militar, algumas leis em relação ao trabalho e ao trabalhador foram instituídas. Entre elas, estão a Lei n. 4.330, de 1 de junho de 1964 (BRASIL, 1964b), que regulava o direito de greve do trabalhador, seguindo o art. 158 da Constituição de 1946, nos termos dessa lei.

Com a legitimidade da greve amparada por essa lei, foram estabelecidos diversos pré-requisitos para que se pudesse realmente fazer greve.

Art. 50 - o exercício do direito de greve deverá ser autorizado por decisão da assembléia geral da entidade sindical que representar a categoria profissional dos associados, por $2 / 3$ (dois terços), em primeira convocação, e por 1/3 (um terço), em segunda convocação, em escrutínio secreto e por maioria de votos.

No presente artigo, é possível identificar os empecilhos para se iniciar a greve de certa categoria. Para Miranda (2016), a Lei n. 4.330 tinha como um dos objetivos o controle da classe trabalhadora. Esse mesmo autor assinala que, no capítulo $V$ da lei citada, é apresentado o direito estabelecido aos grevistas; entre os incisos do artigo $19^{\circ}$, estão a coleta de donativos e o uso de cartazes de propaganda pelos grevistas, desde que não ofensivos e estranhos às reivindicações da categoria profissional. Houve também a proibição de despedida de empregado que tenha participado pacificamente de movimentos grevistas; proibição ao empregador de admitir empregado, em substituição aos grevistas. Já no capítulo VI dessa mesma lei, há um destaque sobre a ilegalidade da greve e, no artigo $22^{\circ}$ inciso III, identifica-se a repressão das ideologias partidárias em relação ao estimulo da greve: III- Se deflagrada por motivos políticos, partidários, religiosos, sociais, de apoio ou solidariedade, sem quaisquer reivindicações que interessem, direta ou indiretamente, à categoria profissional.

Nesse inciso é possível verificar a coação de qualquer organização grevista em prol de ideologias políticas, isto levando em conta que grande parte dos sindicatos da época era motivada por ideais partidários.

O golpe militar de 1964 significou a mais intensa e profunda repressão política que a classe trabalhadora enfrentou na história do país. As ocupações militares e as intervenções atingiram cerca de 2 mil 
entidades sindicais em todo o país. Suas direções foram cassadas, presas e exiladas. (MIRANDA, 2011, p. 3).

Nesse diapasão, o direito de se fazer greve estava amparado por lei, mas os empecilhos para efetivar o movimento grevista foram explorados com amplitude no capítulo VI da lei n. 4.330.

Entre as medidas em relação ao trabalho desse período, são apresentados também decretos, entre eles está o Decreto n. 54.018, de 14 de julho de 1964 (BRASIL, 1964c), que estabelecia a reorganização do Conselho Nacional de Política Salarial, incluindo normas sobre a política salarial do Governo, que logo foi revisto pelo Decreto n. 54.228 de 1 으 setembro de 1964 (BRASIL, 1964d), que estabelecia:

Art.1-Ao Conselho Nacional de Política Salarial é facultado, no exame dos reajustamentos, revisões ou acordos salariais de caráter coletivo, de que trata o Decreto n. 54.018 de 14 Julho de 1964, tomando pôr base o índice resultante da aplicação do disposto no seu artigo $7^{\circ}$ adaptar as taxas encontradas a situações configuradas pela ocorrência, conjunta ou separadamente $[\ldots]$

A composição dos dois decretos era basicamente a mesma, em relação ao reajuste de trabalho, baseado nos últimos 24 meses de salário vigente. A Lei n. 4.725, de 13 de julho de 1965 (BRASIL, 1965b), estabelece normas para o processo dos dissídios coletivos, sendo complementada pela Lei n. 4.903, de 16 de setembro de 1965 (BRASIL, 1965c). Quanto ao artigo 2o, destaca-se a repercussão dos reajustes salariais na comunidade e na economia nacional, a inflação deveria ser levada em conta para o reajuste salarial desse período, porém deve-se levar em conta o alto índice inflacionário do mesmo período que não acompanhava o aumento salarial. Assim, as duas leis anteriores foram reformuladas em alguns aspectos pelo Decreto n. 57.627, de 13 de janeiro de 1966 (BRASIL, 1966a), constando, no inciso I do artigo primeiro dessa lei, que caberia ao Conselho Monetário Nacional informar a previsão do resíduo inflacionário para o período de um ano, com base nas estimativas do orçamento monetário e de acordo com a política econômica e financeira do Governo para que, a partir disto, ocorresse o aumento do salário.

Ocorreu o acréscimo de artigos sobre a Lei n. 4.090, de 13 de julho de 1962 (BRASIL, 1962), que trata do 13º salário, e a Lei n. 4.749, de 12 de 
agosto de 1965 (BRASIL, 1965d), que acrescentou os seguintes incisos ao artigo 1 :

§3-- A gratificação será proporcional

I- na extinção dos contratos a prazo, entre estes incluídos os de safra, ainda que a relação de emprego haja findado antes de dezembro.

II- na cessação da relação de emprego resultante da aposentadoria do trabalhador, ainda que verificada antes de dezembro.

Durante o período do regime militar também foi estabelecido o Fundo de Garantia do Tempo de Serviço (FGTS), de acordo com a Lei n. 5.107, de 13 de setembro de 1966 (BRASIL, 1966b), que prevê:

Art. 2-- Para os fins previstos nesta lei, todas as empresas sujeitas a Consolidação das Leis do Trabalho (CLT) ficam obrigadas a depositar, até o dia 20 (vinte) de cada mês em conta bancaria vinculada, importância correspondente a $8 \%$ (oito por cento) da remuneração paga no mês anterior a cada empregado [...].

Esse artigo previsto em lei possui eficácia até os dias de hoje, garantindo ao trabalhador, em algum momento de seu tempo trabalhado, o direito de sacar o FGTS, ficando claro que ele possa fazer o saque dessas contas. Em 2016, por exemplo, a Medida Provisória n. 763 previa que todo trabalhador que pedisse demissão ou tivesse seu contrato de trabalho encerrado por justa causa (até a data de 31/12/2015) teria direito ao saque das contas inativas de FGTS, podendo retirar seu dinheiro a partir de fevereiro de 2017 (BRASIL, 2016).

Nesse mesmo período, foram confeccionadas diversas leis e decretos. O Decreto-Lei n. 15, de 29 de julho de 1966 (BRASIL, 1966c), trata das normas e critérios para uniformização dos reajustes salariais, sobrepondo-se às leis citadas anteriormente e ao Decreto-Lei n. 15. Já o Decreto-Lei n. 17, de 22 de agosto de 1966 (BRASIL, 1966d), introduz alterações via artigos 1ำ, 5ㅇ e 8o do Decreto-Lei n. 15, o qual prevê em seu Art. 1ㅇ․

Poder Executivo publicará, mensalmente, através de Decreto do Presidente da República, os índices para reconstituição do salário real médio da categoria nos últimos vinte e quatro meses anteriores à data do término da vigência dos acordos coletivos de trabalho ou de decisão da Justiça do Trabalho que tenham fixado valores salariais $[\ldots]$. 
Depois de diversas alterações, a redação do artigo 1으, ficou da seguinte forma:

$\S 1^{\circ}$ - Na determinação final do índice de reajustamento, a sentença do Tribunal poderá tomar ainda em consideração os seguintes fatores:

a) metade do resíduo inflacionário indicado pelo Conselho Monetário Nacional, na forma do artigo $1^{\circ}$ do Decreto n. 57.627[...], de 13 de janeiro de 1966;

b) o percentual referente ao aumento da produtividade nacional no ano anterior, informado pelo Conselho Nacional de Economia;

c) a percentagem concernente à perda do poder aquisitivo médio real, ocorrida entre a instauração e o julgamento do dissídio, apurada segundo os índices a que se refere o "caput" desse artigo [...]

Assim, o artigo 50 do Decreto-Lei n. 15 assinala que a empresa que não apresentasse capacidade financeira para o aumento de salário seria isentada do reajuste. Por outro lado, o Decreto-Lei n. 17 demonstra que a empresa que apresentasse incapacidade de efetuar o aumento, seria suspensa ao "juízo em que se processar a ação de cumprimento intentada, medida que prevalecerá até decisão final do juízo da execução". Nesse diapasão, o artigo 8 do Decreto-Lei n. 15 sintetizava que será obrigatoriamente compensado qualquer aumento salarial, voluntário ou compulsório, inclusive sob a forma de abono ou reclassificação, concedido durante o prazo de vigência de acordo coletivo ou de decisão da Justiça do Trabalho.

O Decreto-Lei n. 17 sofreu o seguinte acréscimo: "salvo se decorrente de aumento individual relativo a término de aprendizagem, promoção, transferência ou equiparação salarial resultante de sentença transitada em julgado." Dessa forma, uma lei vinha para suprir à outra.

No ano de 1967, foi aprovado o Decreto-Lei n. 229, de 28 de fevereiro de 1967 (BRASIL, 1967), que alterou alguns artigos da CLT de 1943, entre eles o artigo $13^{\circ}, 14^{\circ}, 15^{\circ}$, sendo esses dois últimos alterados novamente em $1969^{1}$. Nessa assertiva, o artigo $18^{\circ}$ que trata dos documentos a serem apresentados para serem feitas as anotações na Carteira de Trabalho, também foram alterados (cf. COSTA, 1996).

${ }^{1}$ Texto disponível em: <http://www.planalto.gov.br/ccivil_03/decreto-lei/Del5452.htm>. 
Para contrapor as leis a respeito do reajuste salarial, nota-se que a Lei n. 5.451, de 12 de junho de 1968 (BRASIL, 1968), apresenta logo em seu primeiro artigo as seguintes resoluções:

Art. $1^{\circ}$ Nos cálculos de reajustamentos salariais efetuados pelo Conselho Nacional de Política Salarial, pelo Departamento Nacional de Salário e nos processos de dissídio coletivo perante a Justiça de Trabalho, o novo salário será determinado de modo a equivaler ao salário real médio dos últimos 24 (vinte quatro) meses, com acréscimo de previsão para compensação da metade do resíduo inflacionário fixado pelo Conselho Monetário Nacional e de uma taxa fixada pelo Ministério do Planejamento e Coordenação Geral, que traduza o aumento de produtividade no ano anterior, na forma da legislação vigente.

Junto com os seguintes parágrafos: $\S 1^{\circ}$ o salário da cada um dos últimos, 24 (vinte e quatro), meses, expresso no poder aquisitivo da moeda no mês do reajustamento, será calculado multiplicando-se o salário de cada mês pelo respectivo índice de correção salarial; §2- O Poder Executivo fixará mensalmente os índices de correção salarial para reconstituição do salário real médio da categoria nos últimos 24 (vinte e quatro) meses anteriores à data do término da vigência dos acordos coletivos de trabalho ou de decisão da Justiça do Trabalho que tenha fixado valores salariais. No artigo 3 o da presente lei, será ajustado que as categorias que tiverem aumentos fixados com a lei anterior terão direito a bonificação.

\section{PROCESSOS TRABALHISTAS DO TRIBUNAL REGIONAL DO TRABALHO - TRT - 24A REGIÃO - MS}

Dos processos analisados, três serão contemplados no presente artigo, para dar uma visão concreta das relações trabalhistas entre empregador e empregado. O processo n. 270/189 de 1965, possui três volumes, 68 páginas, e refere-se ao município, apresentando como reclamante: Pedro José de Brito e como reclamado a Construtora San Marcos.

Pedro José de Brito, brasileiro casado, mecânico, domiciliado em Corumbá entrou ccontra a reclamada estabelecida em São Paulo para fins de esclarecimento sobre sua demissão sem justa causa. O reclamante começou a prestar serviços de mecânico para a empresa no ano de 1962, 
primeiramente na cidade de Dourados até ser transferido para Corumbá, onde foi demitido no dia 5 de setembro de 1965. Esse trabalhador alegou que não recebeu:

a) Aviso-prévio de 30 dias no valor de $\mathrm{Cr} \$ 300.000$

b) Indenização de antiguidade (três anos) no valor de $\mathrm{Cr} \$ 900.000$

c) Férias proporcionais (11) dias no valor de $\mathrm{Cr} \$ 110.000$

d) 9/12 de remuneração do $13^{\circ}$ mês de salário no valor de $\mathrm{Cr} \$ 225.000$

Somando valor total de $\mathrm{Cr} \$ 1.535 .000$, ficou registrado, nos autos do processo, que a empresa recebeu a carta precatória para comparecer à audiência marcada para o dia 27/11/1965. As partes compareceram pessoalmente à Junta de Conciliação e Julgamento: a Construtora San Marco, na pessoa do seu preposto Antonio Kester, acompanhado de seu advogado Helio Saschser de Souza, e o reclamante Pedro José de Brito, acompanhado de seu advogado Ubirajara Sebastião de Castro. Nesse dia, o reclamante receberia o valor de $\mathrm{Cr} \$ 82.400$, referente ao saldo de salário. O reclamado apresentou à Junta que o motivo da demissão teria ocorrido pelo mau comportamento do reclamante, que teria agredido dois motoristas com quem trabalhava e consertava de maneira incorreta os automóveis. Nova audiência ocorreu em 18/12/1965, e a reclamada apresentou duas testemunhas que não souberam confirmar a história das brigas e do conserto dos carros, ficando assim decido, nesse dia, que a reclamada deveria pagar ao reclamante o valor total de $\mathrm{Cr} \$ 1.535 .000$ mais a custa do processo, no valor de Cr.\$31.026. Ao ser informada a decisão da audiência, a Construtora San Marco enviou ao Tribunal Regional de Corumbá no dia 03/12/1965 seu recurso ordinário, em que usou cada depoimento registrado das testemunhas a seu favor, alegando que o reclamante era mau funcionário e só não havia sido dispensado antes porque na região não era fácil achar mecânicos de caminhão para prestar serviços. Logo após enviar o recurso ordinário, foi pago o valor estabelecido para a custa do processo.

Após tomar conhecimento do recurso ordinário da Construtora, o reclamante Pedro José de Brito entrou com suas contrarrazões sobre o recurso ordinário da empresa no dia 31/01/1966, alegando que esta dificultava o exercício do trabalho e, como já havia esclarecido, a questão da briga com os funcionários não passou de um mal entendido momentâneo. Após a 
análise da carta precatória e o recurso ordinário exposto pelas partes, ficou deferida a primeira decisão da Junta de Conciliação do TRT de Corumbá de que o valor a ser pago ao reclamante pela reclamada é de $\mathrm{Cr} \$ 1.535 .000$. Anexa ao processo, está a ordem de pagamento com vistas a Pedro José de Brito pelo Banco do Brasil que deveria ser pago ao reclamante, mas ele não recebeu o valor tendo que entrar novamente com o recurso da carta precatória em 04/01/1968. Após um ano de espera pela ordem de pagamento, a solicitação foi novamente enviada à empresa notificando que, se não tivesse realizado a ordem de pagamento, seus bens seriam penhorados para cumprir o valor total do pagamento que agora estava na ordem de Cr\$1.549, 78, incluindo custos processuais. No dia 07/03/1968, Ubirajara Sebastião de Castro, advogado do reclamante, apresentou ao Tribunal a guia de retirada do valor pago pela Construtora San Marco. Dessa forma, o processo foi extinto.

O exemplo do processo citado é utilizado como base dos direitos que o trabalhador buscava garantir durante sua jornada de trabalho. Nesse caso, o trabalhador almejava receber, entre seus direitos trabalhistas e após ser mandado embora, o valor referente ao $13^{\circ}$ salário.

No processo n. 346/1964 verificou-se que o reclamante Ariel Pinto Garcia entrou contra a reclamada para receber seus direitos trabalhistas referentes às horas extras, salário família, adicional noturno, que não foram pagos pelo empregador Ernane Guilherme, durante seu tempo de serviço prestado na Padaria Santo Antonio, exercendo o cargo de forneiro no período de dois meses. Após a abertura do processo na justiça do trabalho, as partes entraram em acordo a respeito do valor que deveria ser pago ao empregado, e o processo foi arquivado.

No processo n. 153/1964, o reclamante José Augusto Nunes entrou na justiça contra a reclamada para a validação da rescisão de seu contrato trabalhista, tendo o reclamante recebido todos seus direitos durante o tempo de serviço prestado na empresa Lundgren Irmãos Tecidos S/A (casas Pernambucanas), sendo o processo extinto.

No processo n. 195/1964, o reclamante Alberto Soares entrou com uma ação contra a reclamada para obter seus direitos trabalhistas, em relação ao tempo de serviço prestado como pedreiro para Armando Soares 
durante um período de seis meses. O processo foi movido pelo fato de o empregado ter sido mandado embora sem justificativa alguma. No dia da audiência, as partes entraram em acordo, e o processo foi arquivado.

No processo n. 170/1964 movido por Ézio Teixeira, que pediu a abertura do processo para homologar seu pedido de demissão, o mesmo exerceu o cargo de balconista durante o período de um mês, tendo sido demitido por livre e espontânea vontade. Ézio recebeu todos os seus direitos por parte da empregadora- Irmãos Baruki, referentes ao tempo de serviço prestado. Após a audiência de conciliação, o processo foi arquivado.

Os exemplos dos processos citados dão uma amostra dos direitos que o trabalhador buscava garantir durante sua jornada de trabalho. No processo n. 270/189 de 1965, por exemplo, o trabalhador buscava receber entre seus direitos após ser mandado embora o valor referente ao $13^{\circ}$ salário, que foi uma das leis que recebeu acréscimo durante o período militar, como já exemplificado anteriormente. Por meio dos comentários sintetizados a respeito do conteúdo de alguns dos processos analisados, foi possível perceber que a motivação processual está relacionada ao recebimento dos direitos trabalhistas, direitos esses que, segundo os princípios internacionais do direito do trabalho e do direito previdenciário, devem visar o homem levando em conta seu valor como ser humano, prevendo a partir disto que seus direitos sejam respeitados segundo seus valores sociais.

\section{CONSIDERAÇÕES FINAIS}

Tendo em vista que esta pesquisa encontra-se em andamento, foi possível analisar apenas o primeiro momento, do período composto pelos anos do regime militar, época de grande instabilidade, principalmente quando se tratava de equiparar o reajuste salarial com a inflação. Assim, verificou-se a aprovação de praticamente uma lei por mês com intuito de adequar a situação do trabalho e do trabalhador à nova realidade do país, o qual vinha passando por período de instabilidade econômica e social.

Em síntese, a análise dos processos se encontra em andamento; com o breve levantamento que vem sendo realizado sobre essas análises, foi possível perceber que o trabalhador buscava a Junta de Conciliação e Julgamento com a finalidade de exigir seus respectivos direitos trabalhistas, 
que se encontravam muito voláteis devido ao momento político em que se passa o período analisado. A continuidade desta pesquisa terá como objetivo explanar de forma mais concreta a situação socioeconômica que o país passava durante o golpe militar a partir da aprovação das leis já citadas anteriormente.

\section{REFERÊNCIAS}

ABREU, Monique Oliveira. Governo João Goulart e a efetivação do Golpe de Estado no Brasil: 1961-1964. 2011. 32f. Trabalho de Conclusão de Curso (Graduação em História) - Universidade Federal de Juiz de Fora (UFJF), Juiz de Fora, MG, 2011. Disponível em: < http://www.ufff.br/historia/files/2013/11/2011-GovernoJo\%C3\%A3o-Goulart-e-a-Efetiva\%C3\%A7\%C3\%A3o-do-Golpe-de-Estado-noBrasil-1961-1964.pdf>. Acesso em: 10 fev. 2017.

BARROS, Edgard Luiz de. Os governos militares. São Paulo: Contexto, 1994. (Coleção repensando a história).

BRASIL. Medida Provisória n. 763, de 22 de dezembro de 2016. Altera a Lei n. 8.036, de 11 de maio de 1990, para elevar a rentabilidade das contas vinculadas do trabalhador por meio da distribuição de lucros do Fundo de Garantia do Tempo de Serviço e dispor sobre possibilidade de movimentação de conta do Fundo vinculada a contrato de trabalho extinto até 31 de dezembro de 2015. Brasília, 2016.

. Lei n. 5.451, de 12 de junho de 1968. Dispõe sobre o reajustamento salarial. 1968. Disponível em: <http://www.planalto.gov.br/ccivil_03/leis/19501969/L5451.htm>.

. Decreto-Lei n. 229, de 28 de fevereiro de 1967. Altera dispositivos da Consolidação das Leis do Trabalho, aprovada pelo Decreto-lei n. 5.452, de 1 o de maio de 1943, e dá outras providencias. 1967. Disponível em: <http://www. planalto.gov.br/ccivil_03/decreto-lei/Del0229.htm>.

. Decreto n. 57.627, de 13 de janeiro de 1966. Regulamenta o artigo $2^{\circ}$ da lei 4.725 de 13 de julho de 1965, com a redação dada pela lei número 4.903 de 16 de dezembro de 1965. 1966a. Disponível em: <http://www2.camara.leg.br/legin/fed/ decret/1960-1969/decreto-57627-13-janeiro-1966-398172-publicacaooriginal-1pe.html>.

. Lei n. 5.107, de 13 de setembro de 1966. Cria o Fundo de Garantia de Tempo de Serviço e dá outras providências. 1966b. Disponível em: <http://www. planalto.gov.br/ccivil_03/leis/L5107impressao.htm>.

. Decreto-Lei n. 15, de 29 de julho de 1966. Estabelece normas e critérios para uniformização dos reajustes salariais e dá outras providências. 1966c. 
Disponível em: <http://www.planalto.gov.br/CCIVil_03/Decreto-Lei/1965-1988/ Del0015.htm>.

. Decreto-Lei n. 17, de 22 de agosto de 1966. Introduz alterações em dispositivos, que menciona do Decreto-lei no 15, de 29 de julho de 1966. 1966d. Disponível em: <http://www.planalto.gov.br/ccivil_03/decreto-lei/1965-1988/ Del0017.htm>.

. Lei n. 4.740, de 15 de julho de 1965. Lei orgânica dos partidos políticos. 1965a. Disponível em: <http://www2.camara.leg.br/legin/fed/lei/1960-1969/lei4740-15-julho-1965-368290-publicacaooriginal-1-pl.html>.

. Lei n. 4.725, de 13 de julho de 1965. Estabelece normas para o processo dos dissídios coletivos, e dá outras providências. 1965b. Disponível em: <http:// www.planalto.gov.br/Ccivil_03/leis/1950-1969/L4725.htm>.

. Lei n. 4.903, de 16 de dezembro de 1965. Dá nova redação ao art. 2o e ao $\S 1$ 으 do art. 6o da Lei n. 4.725, de 13 de julho de 1965, que estabelece normas para o processo dos dissídios coletivos, e dá outras providências. 1965c. Disponível em: <http://www.planalto.gov.br/ccivil_03/leis/1950-1969/L4903.htm>.

. Lei n. 4.749, de 12 de agosto de 1965. Dispõe sobre o pagamento da gratificação prevista na lei n. 4.090, de 13 de julho de 1962. 1965d. Disponível em: <http://www.planalto.gov.br/ccivil_03/leis/14749.htm>.

. Ato Institucional n. 1, de 9 de abril de 1964. Dispõe sobre a manutenção da Constituição Federal de 1946 e as Constituições Estaduais e respectivas Emendas, com as modificações instroduzidas pelo Poder Constituinte originário da revolução Vitoriosa. 1964a. Disponível em: <http://www.planalto.gov.br/ccivil_03/ait/ait-0164.htm>.

. Lei n. 4.330, de 10 de junho de 1964. Regula o direito de grave, na forma do art.158 da Constituição Federal. 1964b. Disponível em: <https://www.planalto. gov.br/ccivil_03/leis/1950-1969/L4330.htmimpressao.htm>.

Decreto n. 54.018, de 14 de julho de 1964. Reorganiza o Conselho Nacional de Política Salarial, estabelece normas sobre a política salarial do governo e da outras providências. 1964c. Disponível em: <http://www.planalto.gov.br/ccivil_03/ decreto/antigos/D54018impressao.htm>.

. Decreto n. 54.228, de 1 ㅇ de setembro de 1964. Dispõe sobre a ação do Conselho Nacional de Política Salarial na aplicação do Decreto n. 54.018, de 14 de julho de 1964. 1964d. Disponível em: <http://www2.camara.leg.br/legin/fed/ decret/1960-1969/decreto-54228-1-setembro-1964-394391-publicacaooriginal1-pe.html>. 
. Lei n. 4.090, de 13 de julho de 1962. Institui a Gratificação de Natal para os Trabalhadores. 1962. Disponível em: <http://www.planalto.gov.br/ccivil_03/ leis/|4090.htm>.

COSTA, Edmilson Silva. A política salarial no Brasil, 1964-1985: 21 anos de arrocho salarial e acumulação predatória. 1996. 443 f. Tese (Doutorado em Economia) Universidade Estadual de Campinas (Unicamp), Campinas, SP, 1996.

HENRIQUES, Luiz Sérgio. As esquerdas a ditadura e o problema da frente democrática. In: ARAÚJO, Caetano Pereira de. 1964: as armas da política e a ilusão armada. Brasília: Fundação Astrojildo Pereira, 2014. p. 35-45

JUSTIÇA DO TRABALHO- 2a Região. Junta de Conciliação e Julgamento de Corumbá MT. Processo n. 270/1965 (apenso- processo n. 39/68). . Junta de Conciliação e Julgamento de Corumbá MT. Processo n. 346/1964. . Junta de Conciliação e Julgamento de Corumbá MT. Processo n. 153/1964. . Junta de Conciliação e Julgamento de Corumbá MT. Processo n. 195/1964. . Junta de Conciliação e Julgamento de Corumbá MT. Processo n. 195/1964. . Junta de Conciliação e Julgamento de Corumbá MT. Processo n. 170/1964.

MIRANDA, Agenor Gabriel Chaves. O direito do trabalho na ditadura civil-militar. Conteúdo Jurídico, Brasília, DF, 13 set. 2016. Disponível em: <http://www. conteudojuridico.com.br/?artigos\&ver=2.56747\&seo=1 >. Acesso em: 3 jun. 2017. MIRANDA, Maria. História do Sindicalismo no Brasil. Revista Virtual Direito Brasil, v. 5, n. 1, 2011.

MOTTA, Carlos Guilherme; LOPEZ, Adriana. História do Brasil: uma interpretação. 2. ed. São Paulo: SENAC, 2008. 